\title{
Política de inserção de servidores com deficiência na universidade: o olhar dos gestores
}

\author{
EeliseSantosSaga Mestra em Administração Universitária. Universidade Federal de Santa Catarina (UFSC) - Brasil. \\ lisoka23@gmail.com \\ GrlaCistinaDtraBúigo Doutora em Educação. Universidade Federal de Santa Catarina (UFSC) - Brasil. \\ carla.burigo@ufsc.br
}

\begin{abstract}
RESUMO
Este artigo é um recorte de uma pesquisa maior (SOUSA, 2018) que buscou compreender como se desenvolve, no olhar dos gestores, a política de inserção dos servidores técnico-administrativos em educação, com deficiência, da Universidade Federal de Santa Catarina. A pesquisa caracteriza-se por ser qualitativa, documental e bibliográfica com aplicação de entrevistas semiestruturadas com gestores que possuem servidores com deficiência em suas unidades admitidos até janeiro de 2018. A análise das informações coletadas foi realizada por meio de análise de conteúdo, buscando compreender a visão dos gestores sobre a inserção de servidores com deficiência na Instituição. Ficou evidenciado, por meio dos resultados, que os gestores compreendem e confirmam a efetividade da política de inserção de servidores com deficiência no que tange ao ingresso na Instituição. Porém, apontam para uma inexistência de medidas de acompanhamento desse público durante sua vida funcional, após encerrado o estágio probatório. Uma contradição se evidenciou neste estudo, ao mesmo tempo em que a Instituição é inclusiva observando a legislação vigente de ingresso de servidores com deficiência, ela nega a inserção deste servidor, por falta de uma política institucional inclusiva no desenvolvimento da carreira do servidor. Receber esses profissionais dentro da Instituição e lhes fornecer as ferramentas necessárias para o desenvolvimento de suas atividades deixa de ser apenas uma obrigação legal, passa a ser um cumprimento de responsabilidade dentro da sociedade a qual está inserida. A inclusão social traz consigo a equiparação de oportunidades, em uma Universidade, como Instituição Social.
\end{abstract}

Palavras-chave: Deficiência. Inclusão. Política Institucional de Inclusão. Política Pública. UFSC.

\section{Insertion policy for servers with disabilities in the university: the managers point of view}

\begin{abstract}
This article is part of a bigger research (SOUSA, 2018) that aimed to analyze the insertion policy of the technicaladministrative workers with disabilities, in education, at the Federal University of Santa Catarina, and in the managers' perspective. This research was characterized as qualitative, documental and bibliographic, and used the application of semi-structured interviews with managers who had workers with disabilities in their units, and who were admitted until January 2018. The analysis of the information collected was made through content analysis, seeking to understand the managers' view about the inclusion of disabled employees in the Institution. The results showed that the managers understand and confirm the effectiveness of the Public Policy for the Inclusion of Workers with Disabilities regarding their admission into the Institution. However, they highlight the lack of measures to follow this public during their functional life after the probationary period. A contradiction is evident: at the same time that the Institution is inclusive, observing the current legislation on the admission of disabled employees, it denies their inclusion, due to the inexistence an inclusive institutional policy for the development of the career of these workers. Receiving these workers into the Institution and providing them with the necessary tools to carry out their activities is not only a legal obligation, it's also a social responsibility. Social inclusion brings along the equality of opportunities within the University as a Social Institution.
\end{abstract}

Keywords: Disabilities. Inclusion. Institutional Policy of Inclusion. Public Policy. UFSC. 


\section{INTRODUÇÃO}

Este artigo é um recorte de uma pesquisa maior (SOUSA, 2018), que trata da Política Institucional de Inclusão de servidores técnico-administrativos em educação, com deficiência, na Universidade Federal de Santa Catarina, campusFlorianópolis, Santa Catarina.

A Universidade Federal de Santa Catarina, como instituição pública de ensino superior, tem um papel relevante diante do processo de desenvolvimento da comunidade em que está inserida. Sua missão é:

[...] produzir, sistematizar e socializar o saber filosófico, científico, artístico e tecnológico, ampliando e aprofundando a formação do ser humano para o exercício profissional, a reflexão crítica, solidariedade nacional e internacional, na perspectiva da construção de uma sociedade justa e democrática e na defesa da qualidade de vida (UFSC, 2015, p. 22).

A inclusão social perpassa por uma das ações que materializa a missão da Universidade (UFSC, 2015). Para Sassaki (1997), inserção social é um processo de adaptação tanto da pessoa que possui alguma necessidade de adaptação de acessibilidade, como da sociedade em que ela está inserida, para que assim todos tenham as mesmas oportunidades de acesso e permanência.

Na atualidade, temas referentes à inclusão, diversidade e responsabilidade social estão cada vez mais fazendo parte do cotidiano das organizações e da população. Neste contexto, observa-se o esforço crescente por parte de vários segmentos em contribuir para definição de uma sociedade mais justa que, por meio de mudanças atitudinais, possam vivenciar a implementação de uma cultura organizacional baseada em valores socioambientais e no respeito às diferenças e à valorização das pessoas. (CARDOSO, 2013, p. 28).

No processo de interação com a sociedade, a Universidade legitima o seu papel social também por meio de ações que materializem a inserção social. Isso se deve ao fato de a Universidade ser uma instituição social, ou seja, que realiza prática social, que por meio de suas ações the é conferida pela sociedade, sua legitimidade (CHAUÍ, 2003).

Por meio de concurso público, com vagas reservadas, conforme previsto na Lei ํ․ 8.112/90 (BRASIL, 1990), a UFSC recebe servidores técnico-administrativos em educação com deficiências para atuarem em diferentes setores da Instituição.

A inserção de servidores técnico-administrativos em educação com deficiência, contemplada pela legislação no. 8.112/90 (BRASIL, 1990), requer uma política de gestão que perpasse pelas condições de trabalho, bem como, pelo conhecer as limitações e potencializar ações de modo que este servidor tenha identidade e sentimento de pertencimento ao seu ambiente de trabalho, como qualquer outro servidor da Instituição.

Isto posto, a inquietação que se objetiva neste Estudo (SOUSA, 2018), foi de compreender como se desenvolve, no olhar dos gestores, a política de inserção dos servidores técnico-administrativos em educação, com deficiência, na Universidade Federal de Santa Catarina., visto que, do ponto de vista dos servidores, ainda existem lacunas a serem preenchidas no sentido de mudar a cultura de inclusão da pessoa com deficiência, conforme aponta pesquisa realizada por Cardoso (2013, p. 111):

[...] a UFSC precisa trabalhar as suas práticas de seleção de valores, de modo que estes sejam realmente voltados ao empreendimento da responsabilidade social e da inclusão do PcD1. Também, a Instituição precisa garantir que o comportamento da alta administração esteja totalmente aderente à perspectiva da inclusão e, por fim, é essencial implantar métodos e ferramentas de socialização dos referidos valores.

Com vistas a atender o objetivo inicialmente proposto, para o desenvolvimento deste artigo, iniciamos do que dispúnhamos de mais concreto, ou seja, os Servidores Técnico-Administrativos em Educação

\footnotetext{
${ }^{1}$ PcD - Pessoa com Deficiência
} 
(STAE) com deficiência, ingressantes na Instituição até janeiro de 2018, por meio do Edital no 015/DDP/2016 (UFSC, 2017a). Após, buscamos conhecer a Política Institucional de inserção social de servidores TAE, com deficiência na UFSC. E, por fim, descrevemos diretrizes da Política Pública de inserção social de servidores técnico-administrativos em educação com deficiência nas universidades públicas federais. Ao final, percorremos um caminho inverso, retornando ao ponto de partida revelando outras nuances que esta caminhada possa nos proporcionar.

O caminho teórico/metodológico proposto neste estudo está embasado nos pressupostos teóricos de Triviños (2009) que propõe que devemos partir, no desenvolvimento da investigação, do nosso concreto sensível. Ou seja, daquilo que mais conhecemos, da nossa materialidade primeira. Neste Estudo, os servidores TAE com deficiência na UFSC. Após, vamos apropriando-nos da realidade, com vistas a melhor conhecer o fenômeno investigado, buscando a sua essência. Esta realidade trilhada pode se transformar em categorias de modo a sustentar teoricamente a investigação proposta. Partimos do concreto e voltamos a ele, desvelando outros olhares que esta caminhada possa nos propiciar.

\section{SERVIDORES TAE COM DEFICIÊNCIA NA UFSC}

A UFSC conta com aproximadamente 3.242 servidores técnico-administrativos em educação (UFSC, 2017b) trabalhando nas diversas áreas da Instituição. Dentre estes, existem aproximadamente 72 servidores que possuem algum tipo de deficiência.

O ingresso de servidores públicos com deficiência é respaldado pela Lei oㅡ 8.112/90 (BRASIL, 1990), que dispõe sobre o Regimento Jurídico Único dos Servidores Públicos Civis da União, das Autarquias e das Fundações Públicas Federais. A Lei no 8.112/90 (BRASIL, 1990) garante que seja reservado um percentual mínimo de $5 \%$ e máximo de $20 \%$ das vagas oferecidas em concursos para pessoas com deficiência.

No ano de 2016, a UFSC realizou o concurso público no 015/DDP/2016 (UFSC, 2017a), que contou com 15.401 candidatos inscritos, destes, 237 concorrendo para vagas reservadas para pessoas com deficiência. Após todo processo de seleção do concurso, foram aprovados 656 candidatos, entre eles 23 candidatos com deficiência.

Segundo a Divisão de Movimentação/Departamento de Desenvolvimento de Pessoas/Pró-Reitoria de Desenvolvimento e Gestão de Pessoas, após tomarem posse, os servidores passam por entrevista para análise de seu perfil e, também, são analisadas as demandas dos setores de trabalho com vistas à melhor lotação do servidor, respeitando suas potencialidades e deficiência. Algumas das deficiências dos servidores admitidos até janeiro/2018, requerem adaptação para o desenvolvimento de suas atribuições em seus ambientes de trabalho.

Dos 23 candidatos com deficiências aprovados no Concurso, por meio do Edital no 015/DDP/2016 (UFSC, 2017a), apenas 19 foram admitidos na UFSC até janeiro de 2018. Os 19 servidores admitidos, possuem as seguintes deficiências:

- 03 deficiência auditiva;

- 07 deficiência física; $e_{\text {, }}$

- 09 deficiência visual.

A Universidade, quando recebe o servidor, necessita inicialmente conhecê-lo e a sua deficiência, com vistas a possibilitar uma melhor inserção, reduzindo as possíveis desigualdades no ambiente de trabalho.

Para tanto, mesmo a inserção social estando contemplada na legislação vigente (BRASIL, 1990), se fazem pertinentes ações no contexto da gestão universitária para que esta inserção se materialize. Ou seja, que busque mecanismos de permanência e de boas condições de trabalho ao servidor com deficiência em uma Universidade, como instituição social (CHAUÍ, 2003).

De acordo com Chauí (2003), a gestão universitária deve levar em conta sua função social, os atores envolvidos, assim como os processos. Todavia, muito além do instituído pelas diretrizes da Política Pública, representada pelo Estado, a gestão universitária vivencia a dualidade do que é necessário fazer e do que potencialmente deseja concretizar, indo ao encontro dos preceitos e suas próprias raízes que a define (REIS, 2016). 
A gestão universitária se sustenta inicialmente pelas diretrizes da política institucional que delineia o caminho a ser percorrido pelos gestores e, neste Estudo, a Política Institucional de Inserção de Servidores com Deficiência.

\subsection{Política institucional de inserção de servidores com deficiência}

Historicamente a Universidade Brasileira, desde a década de 1920, vem buscando por meio de ações que se fomentam também na Política Pública, a inclusão no ensino superior. Segundo Eco (2014, s/p), sobre este espaço social ocupado pela Universidade, ela é ainda é,

[...] o lugar em que podem proliferar confrontos e discussões, ideias melhores por um mundo melhor, o reforço e a defesa de valores fundantes universais, não ordenados nas estantes de uma biblioteca, mas difundidos e propagados pelos meios os mais distintos.

Diante do contexto histórico da instituição Universidade, este é um espaço diverso e inclusivo, no sentido de fomentar ações que possam atender a toda população que a cerca, dentro de suas especificidades (BIANCHETTI; SGUISSARDI, 2017; CHAUÍ, 2003). A UFSC como Instituição Social (CHAUÍ, 2003), historicamente vem respondendo aos desafios sociais que a ela são pertinentes. Desenvolve-se no compasso do desenvolvimento da sociedade, que é inserida. A Política Institucional de Inclusão de Servidores com Deficiência, também vem nesta mesma instância tendo seu nascedouro na área de Gestão de Pessoas da Instituição, inicialmente pelo ato da admissão, em observância a Lei no 8.112/90 (BRASIL, 1990).

A Pró-Reitoria de Desenvolvimento e Gestão de Pessoas (PRODEGESP) é responsável pelo desenvolvimento da área de Gestão de Pessoas, bem como pelo processo de inserção social dos servidores com deficiência na Instituição (UFSC, 2017c), e foi criada com o objetivo de

[...] auxiliar o Reitor em suas tarefas executivas na área de desenvolvimento e gestão de pessoas, almejando o fortalecimento das atividades de ensino, pesquisa e extensão, bem como um melhor nível de qualidade de vida no trabalho aos servidores docentes e técnicoadministrativos em educação. (UFSC, 2017c, p.01).

Esta Pró-Reitoria foi criada em 2016, e tem na sua essência ações que potencializem a tônica e o fortalecimento do desenvolvimento humano e social. Constituída pela tríade administração de pessoal, desenvolvimento, e atenção à saúde, seu propósito estruturante, filosófico e ideológico é contextualizar o servidor como sujeito do seu trabalho e não mero objeto de sua produção (UFSC, 2017d).

Além da PRODEGESP como órgão responsável pelo processo de gestão no que tange à inserção e busca de mecanismos para a permanência do servidor na Instituição, há também como Política Institucional de Inserção de Servidores com Deficiência, em observância ao Decreto no 3.298/1999 (BRASIL, 1999), a Equipe Multiprofissional de Acompanhamento aos Servidores da UFSC com Deficiência e em Estágio Probatório (EMAPCD), que trata da Política Nacional para Integração da Pessoa Portadora de Deficiência, dando suporte à PRODEGESP.

De acordo com o Decreto oㅜ 3.298/1999 (BRASIL, 1999, art.․ 43), compete à Equipe Multiprofissional:

$\S 1$ A equipe multiprofissional emitirá parecer observando:

I - as informações prestadas pelo candidato no ato da inscrição;

II - a natureza das atribuições e tarefas essenciais do cargo ou da função a desempenhar;

III - a viabilidade das condições de acessibilidade e as adequações do ambiente de trabalho na execução das tarefas;

IV - a possibilidade de uso, pelo candidato, de equipamentos ou outros meios que habitualmente utilize; $\mathrm{e}$,

$V$ - a CID6 e outros padrões reconhecidos nacional e internacionalmente.

§2 A equipe multiprofissional avaliará a compatibilidade entre as atribuições do cargo e a deficiência do candidato durante o estágio probatório. 
As principais atribuições desta equipe visam identificar a viabilidade das condições de acessibilidade e as adequações do ambiente de trabalho do servidor com deficiência; e, avaliar a compatibilidade entre as atribuições do cargo e a deficiência do servidor durante o estágio probatório (UFSC, 2017e).

A Equipe inicia sua atuação durante o processo do concurso público, com vagas reservadas para pessoa com deficiência. Após aprovação, a Equipe faz o acompanhamento dos setores onde estes servidores serão lotados, quais funções irão desempenhar, se possuem estrutura para o recebimento destes servidores ou se precisam de alguma adaptação para o desenvolvimento de suas atividades profissionais. Este acompanhamento permanece durante todo estágio probatório do TAE. Após o encerramento do estágio probatório, a Equipe continua atuando sempre que solicitado (UFSC, 2017e).

Além da PRODEGESP e da EMAPCD, a busca por uma Instituição cada vez mais inclusiva e que entenda a diversidade que temos na sociedade, desempenhando assim seu papel como Instituição social (CHAUÍ, 2003) e no sentido de atender a demanda tanto de servidores como de estudantes, dentro de políticas de ações afirmativas e diversidades, a UFSC criou, em 2016, a Secretaria de Ações Afirmativas e Diversidades (SAAD) (UFSC, 2017f).

A Secretaria de Ações Afirmativas e Diversidades foi criada com o objetivo de auxiliar o Reitor a propor, implementar, consolidar e monitorar políticas de ações afirmativas e diversidades no âmbito da UFSC, contribuindo para a concretização e o fortalecimento de seu papel social (UFSC, 2017f).

Todos estes espaços institucionais, PRODEGESP, SAAD e EMAPCD, são corresponsáveis pela política de inserção dos servidores com deficiência na UFSC. No ano de 2017, a UFSC contava com cerca de 72 servidores técnico-administrativos em educação com alguma deficiência trabalhando nas diversas unidades acadêmicas e administrativas, por isso o trabalho desses setores, de maneira interligada, é de extrema importância para o crescimento de uma Instituição socialmente inclusiva.

A Universidade tem a função de contribuir para a transformação da sociedade em que está inserida por meio do conhecimento (CHAUí, 2003). Esta inclusão fomentada pela Universidade se materializa por meio da gestão universitária, respaldada pela Política Institucional, que reflete as diretrizes da Política Pública. Contudo, a Universidade, como Instituição Social (CHAUÍ, 2003), tem a potencialidade de refletir so bre as raízes que a constitui, podendo ser legitimadora ou opositora da Política Pública que a contextualiza.

\subsection{Política pública de inclusão de servidores com deficiência}

A sociedade muitas vezes enxergou a pessoa com deficiência como alguém sem capacidade para desenvolver as atividades, tanto no local de trabalho, como na vida pessoal (MACHADO, 2001).

Sassaki (1997) divide a inserção da pessoa com deficiência em duas partes: a integração e a inclusão. A parte da integração, por volta das décadas de 1950 a 1980, é marcada pela criação de centros de reabilitação com a intenção de modificar a pessoa com deficiência para que se tornasse apta ao convívio em sociedade em seus diversos meios (familiar, escolar, recreativo). A concepção de inclusão, iniciado na década de 1990, segue com o pressuposto de modificar a sociedade para que esta aceite o deficiente, e ele possa ser mais autônomo e independente.

Historicamente, por meio da Política Pública, para além da integração e da inclusão, a partir do segundo milênio, a sociedade requer a acessibilidade, que se materializa por meio da Lei $n$ o 10.098/2000 (BRASIL, 2000).

A Lei no 10.098/2000 (BRASIL, 2000), estabelece normas gerais e critérios básicos para a promoção da acessibilidade das pessoas portadoras de deficiência ou com mobilidade reduzida, e dá outras providências.

Segundo o Censo Demográfico de 2010 (IBGE, 2012), o Brasil tem 45,6 milhões de pessoas com deficiência. Ou seja, dos cerca de 190 milhões de brasileiros, aqueles com pelo menos uma deficiência, seja visual, auditiva, motora ou mental, somam $23,9 \%$.

A Lei no 7.853/89 (BRASIL, 1989) apresenta diretrizes de apoio às pessoas com deficiência na sua integração social, institui a tutela jurisdicional de interesses coletivos ou difusos dessas pessoas, disciplina a atuação do Ministério Público, define crimes, e dá outras providências no amparo ao deficiente. 
Além das prerrogativas quanto às condições de trabalho da Lei no 7.853/89 (BRASIL, 1989), o Decreto no 3.298/99 (BRASIL, 1999, art.. 37) é um marco da Política Pública de Inclusão de Servidores com Deficiência, pois versa sobre a garantia de participação de pessoas com deficiência em concursos públicos, "[...] em igualdade de condições com os demais candidatos, para provimento de cargos cujas atribuições sejam compatíveis com a deficiência de que é portador". A pessoa com deficiência concorrerá a todas as vagas, sendo, porém, reservado, no mínimo, o percentual de cinco por cento em face da classificação obtida.

Em observância ao processo histórico de desenvolvimento das Leis e Decretos, da década de $1960 \mathrm{e}$ início do segundo milênio, passando pela Constituição Federativa (BRASIL, 1988), que serviram de sustento tanto para a Política Pública de Inclusão de Servidores com Deficiência como políticas inclusivas da pessoa com deficiência de maneira geral, é instituído no ano de 2015 o Estatuto da Pessoa com Deficiência, por meio da Lei oㅗ 13.146/2015 (BRASIL, 2015, art.․2), que considera a pessoa com deficiência,

[...] aquela que tem impedimento de longo prazo de natureza física, mental, intelectual ou sensorial, o qual, em interação com uma ou mais barreiras, pode obstruir sua participação plena e efetiva na sociedade em igualdade de condições com as demais pessoas.

O objetivo desta Lei (BRASIL, 2015) é o de garantir o direito à igualdade da pessoa com deficiência, sem discriminação de qualquer espécie. Apesar disso, como aponta Diniz (2012, p. 70), ainda é recente a compreensão da deficiência como um estilo de vida particular, pois "diferentemente de outros modos de vida, a deficiência reclama o direito de estar no mundo. E o maior desafio para a concretização desse direito é o fato de que se conhece pouco sobre deficiência". Conhece-se pouco a realidade do deficiente, e menos ainda seus direitos assegurados em lei.

Neste contexto, a Universidade, como Instituição Social (CHAUÍ, 2003), necessita apoiar-se nas Políticas Públicas existentes para inclusão de servidores com deficiência e materializar essa inclusão por meio da Política Institucional, possibilitando que seus gestores compreendam a importância desta inclusão e contribuam para que os servidores com deficiência se sintam fazendo parte da Instituição, como sujeito de sua construção.

\section{METODOLOGIA}

A metodologia realizada para o desenvolvimento desta pesquisa (SOUSA, 2018), inicialmente, foi uma pesquisa documental, bibliográfica, entrevista semiestruturada, com levantamento de informações necessárias para a análise de conteúdo. Quanto à abordagem, é uma pesquisa qualitativa.

A pesquisa qualitativa responde a questões muito particulares. Ela se preocupa, nas ciências sociais, com um nível de realidade que não pode ser quantificado. Ela trabalha com o universo dos significados, motivos, aspirações, valores e atitudes, o que corresponde a um espaço mais profundo das relações, dos processos e dos fenômenos que não podem ser reduzidos apenas à operacionalização de variáveis (MINAYO, 2015).

A pesquisa é de natureza aplicada, pois "[...] objetiva gerar conhecimentos para aplicação prática, dirigida à solução de problemas específicos. Envolve verdades e interesses locais" (KAUARK, 2010, p. 27).

Quanto aos fins, o nível de pesquisa é considerado descritivo. Segundo Cervo, Bervian e Silva (2007, p. 32),

[...] a descrição constitui a habilidade de fazer com que o outro veja mentalmente aquilo que o pesquisador observou. Em outras palavras, a descrição deve ser suficientemente precisa para que o interlocutor, ou o leitor, seja capaz de visualizar exatamente aquilo que 0 pesquisador observou.

Na presente pesquisa (SOUSA, 2018), foi descrito como se desenvolve, no olhar dos gestores, a política de inserção de servidores técnico-administrativos em educação, com deficiência, da Universidade Federal de Santa Catarina. 
Quanto aos meios, a pesquisa se sustentou no estudo de caso, na pesquisa documental e bibliográfica, pois as informações coletadas foram elementos essenciais que permitiram melhor compreender o fenômeno investigado. Segundo Chizzotti (2010, p. 135), o estudo de caso

[...] objetiva reunir os dados relevantes so bre o objeto de estudo e, desse modo, alcançar um conhecimento mais amplo sobre esse objeto, dissipando as dúvidas, esclarecendo questões pertinentes e, sobretudo, instruindo ações posteriores.

Para a escolha dos sujeitos da pesquisa, fez-se necessário definir sujeito e realizar um marco temporal de acordo com os objetivos propostos. Segundo Vergara (2013, p. 46), o sujeito dá lugar a população amostral ou amostra:

[...] população não é o número de habitantes de um local, como é largamente conhecido o termo, mas um conjunto de elementos que possuem as características que serão objeto de estudo. População amostral ou amostra é uma parte do universo (população) escolhida segundo algum critério de representatividade.

Os sujeitos participantes desta Pesquisa (SOUSA, 2018), são gestores das unidades administrativas e acadêmicas da Universidade Federal de Santa Catarina, que possuem servidores portadores de deficiência, ingressantes por meio do Edital oㅡ 015/DDP/2016 (UFSC, 2017a), nomeados até janeiro de 2018 do Campus David Ferreira Lima, de Florianópolis.

Como recorte da pesquisa, foram trabalhados apenas com servidores portadores de deficiências do Campus de Florianópolis, não alcançando os Campi de Blumenau, Joinville, Araranguá e Curitibanos. Os 19 servidores nomeados, até janeiro de 2018, foram distribuídos em 14 unidades administrativas e acadêmicas da UFSC, sendo que algumas dessas unidades receberam mais de um servidor portador de deficiência.

Porém, em função do cronograma do desenvolvimento da pesquisa (SOUSA, 2018) e ao número elevado de gestores para realização das entrevistas, foi necessária uma seleção de gestores para a aplicação do instrumento de coleta de informações. Neste sentido, o critério

utilizado foi a escolha de 01 gestor da unidade administrativa central, 01 gestor de unidade administrativa e 01 gestor de unidade acadêmica por área de conhecimento, definidas pela CAPES (CAPES, 2017), totalizando 09 gestores. Vide Quadro 01 - Sujeitos da Pesquisa.

\begin{tabular}{|c|c|c|c|}
\hline \multicolumn{4}{|c|}{ Quadro 01 - Sujeitos da Pesquisa } \\
\hline Área de Atuação do Gestor & ÁREA DE CONHECIMENTO & № GESTORES & \begin{tabular}{|l|} 
No \\
SERVIDORES \\
PORTADOR DE \\
DEFICIÊNCIA
\end{tabular} \\
\hline $\begin{array}{l}\text { Secretaria de Ações } \\
\text { Diversidades }\end{array}$ & e|--- & 01 & 01 \\
\hline Biblioteca Central & -.-- & 01 & 01 \\
\hline Centro de Ciências da Saúde & Ciências da Saúde & 01 & 01 \\
\hline Centro de Ciências Agrárias & Ciências Agrárias & 01 & 01 \\
\hline Centro de Ciências Físicas e Matemáticas & Ciências Exatas e da Terra & 01 & 01 \\
\hline Centro Ciências de Educação & Ciências Humanas & 01 & 01 \\
\hline Centro de Comunicação e Expressão & Ciências Sociais Aplicadas & 01 & 01 \\
\hline Centro de Ciências Biológicas & Ciências Biológicas & 01 & 01 \\
\hline Centro Tecnológico & Engenharias & 01 & 01 \\
\hline TOTAL DOS SUJEITOS ENTREVISTADOS & & 09 & 09 \\
\hline
\end{tabular}

Fonte: SOUSA (2018). 
Os gestores entrevistados foram os chefes imediatos, que têm contato direto com os servidores portadores de deficiência na unidade de lotação, e acompanham com mais proximidade o desempenho do servidor no ambiente de trabalho.

Após definir os sujeitos da pesquisa e o Instrumento de Coleta de Informações (SOUSA, 2018), foram realizadas entrevistas com os sujeitos da pesquisa. A coleta de informações primária ocorreu, por meio de entrevistas semiestruturadas. Segundo Triviños (2009, p. 146),

[...] entrevista semiestruturada é aquela que parte de certos questionamentos básicos, apoiados em teorias e hipóteses, que interessam à pesquisa, e que, em seguida, oferecem amplo campo de interrogativas, fruto de novas hipóteses que vão surgindo à medida que se recebem as respostas do informante.

A coleta das informações ocorreu, por meio de entrevistas semiestruturadas, no período de 16 de a 30 de abril de 2018 e tiveram duração de 20 a 40 minutos cada. Todas as entrevistas foram gravadas, mediante autorização prévia do entrevistado (SOUSA, 2018). Dos nove sujeitos previamente definidos, vide Quadro 01 Sujeitos da Pesquisa, foram entrevistados sete. Dois gestores não dispuseram de tempo em suas agendas para a entrevista no período proposto.

Para obtenção das informações secundárias, utilizamos, na análise documental, documentos fornecidos pela Equipe Multiprofissional e pelo Departamento de Desenvolvimento de Pessoas/UFSC, assim como o Plano de Desenvolvimento Institucional (UFSC, 2015).

As informações coletadas, com respaldo no referencial teórico desenvolvido na pesquisa (SOUSA, 2018), foram analisadas por meio da análise de conteúdo. Segundo Triviños (2009, p.160), análise de conteúdo é

[...] um conjunto de técnicas de análise das comunicações, visando, por procedimentos sistemáticos e objetivos de descrição do conteúdo das mensagens, obter indicadores quantitativos ou não, que permitam a inferência de conhecimentos relativos às condições de produção/recepção das mensagens.

Para o desenvolvimento da análise de conteúdo, bem como para a constituição do instrumento de coleta de informações, fez-se necessário definir preliminarmente catego rias e os seus respectivos conteúdosbase. Potencialmente três categorias foram delineadas:

a) Servidores TAE com deficiência na UFSC: por meio desta categoria, buscamos conhecer a visão dos gestores em relação ao recebimento dos servidores com deficiência em seu ambiente de trabalho, assim como a percepção das possíveis dificuldades encontradas;

b) Política Institucional de Inserção dos Servidores TAE com deficiência: o objetivo desta categoria foi de compreender como os gestores concebem a Política Institucional de Inclusão de Servidores com Deficiência e o que pode ser feito para o acolhimento destes servid ores dentro da Instituição;

c) Política Pública de Inclusão de Servidores com Deficiência: nesta categoria, o objetivo foi compreender como os gestores concebem a Política Pública e de que forma ela interage com a Política Institucional de Inclusão de Servidores com Deficiência.

Cheptulin (1982, p. 05) define categorias como:

[...] a definição da natureza das categorias, de seu lugar e de seu papel, no desenvolvimento do conhecimento está diretamente ligada à resolução do problema da correlação entre o particular e o geral na realidade objetiva e na consciência, assim como à colocação em evidência da origem das essências ideais e da relação destas últimas com as formações materiais, com os fenômenos da realidade objetiva.

A definição da categoria deve ter como preocupação básica o conteúdo nela inserido. 0 que diferencia basicamente uma categoria da outra é o conteúdo. E diante de tantas informações, esta tarefa se torna complexa, necessitando ser discutida, analisada e definida a partir da clareza dos conteúdos. 
Os conteúdos das categorias, necessariamente não devem estar presentes em cada entrevista, de forma sistemática, de acordo com o roteiro da entrevista (TRIVIÑOS, 2009). Pois, nem sempre todas as entrevistas contêm a mesma numeração das perguntas, devido ao roteiro da entrevista (SOUSA, 2018) ser semiestruturado, ou seja, composto por perguntas básicas e derivadas.

Após o encerramento das entrevistas, passamos para a fase de transcrição, atribuindo códigos de identificação aos entrevistados, garantindo assim o sigilo e anonimato dos gestores (G1 - Gestor 01, G2 Gestor 02, [...], G7 - Gestor 07). Cabe ressaltar que cada entrevista foi analisada exaustivamente, para chegar a um corpo de informações que representa o saber do entrevistado sobre o assunto abordado. Ou seja, representa o que conseguimos atingir, de acordo com as informações coletadas, a teoria estudada e o objetivo inicialmente proposto.

\section{ANÁLISE E DISCUSSÃO DOS RESULTADOS}

Como já mencionado no presente estudo, os entrevistados são gestores que receberam em suas unidades servidores técnico-administrativos em educação, com deficiência, ingressantes por meio do Edital no 015/DDP/2016 (UFSC, 2017a).

Gil (2014, p. 17), concebe a área de gestão de pessoas como "[...] função gerencial que visa à cooperação de pessoas que atuam nas organizações para o alcance dos objetivos tanto organizacionais quanto individuais", ou seja, em se tratando da universidade e do objetivo deste estudo, buscou-se pelos gestores que trabalham diretamente na relação organizacional dos novos servidores técnico-administrativos em educação, com deficiência.

Os gestores entrevistados são chefes imediatos destes servidores, ocupando cargos de Chefe de Expediente, Diretor, Coordenador, Coordenador de Curso e Chefe de Departamento. As entrevistas foram realizadas no local de trabalho destes gestores.

Entre os gestores que fizeram parte da pesquisa, havia quatro servidores técnico-administrativos em educação e três servidores docentes. Quanto ao tempo de ingresso na UFSC, um gestor ingressou há 33 anos na Instituição, os demais têm de três anos a dez anos de serviços na UFSC. Em relação ao tempo que ocupam o cargo de gestor, o tempo médio é entre dois a quatro anos de exercício em cargo de gestão em diferentes níveis hierárquicos na Instituição.

A primeira categoria de análise, Servidores TAE com Deficiência na UFSC admitidos por meio do Edital no 015/DDP/2016 (UFSC, 2017a), que entraram em exercício até janeiro de 2018, se sustenta por meio dos seguintes conteúdos base: acolhimento e concepção de inserção social.

Dentre os Servidores apresentam três tipos de deficiência, descritas pelo Decreto no. 3.298/99 (BRASIL, 1999, art.o 3o), são elas: deficiência física, deficiência auditiva e deficiência visual.

Inicialmente, procuramos saber sobre o processo de acolhimento do servidor com deficiência no ambiente de trabalho, assim como a visão do gestor em relação ao processo de inserção social deste servidor. Destacamos a fala do Gestor (G01):

[...] da nossa parte acho que tentamos fazer o possível para que ela se sinta bem. No início eu tive uma conversa com ela, volta e meia a gente conversa. Que ela deveria se sentir plenamente no ambiente de trabalho, se tivesse alguma coisa interferindo que pudesse ajudar. As pessoas do setor acolheram ela muito bem, as pessoas são bem despachadas, tranquilas. Então não teve muito problema. Não teve problema algum. Pelo menos de minha parte eu vejo isso.

Os gestores foram unânimes em dizer que o processo de acolhimento em seus setores ocorreu de forma natural, não tendo problemas por parte dos colegas de trabalho nem para adaptação do ambiente.

[...] primeiro a pessoa com deficiência é um ser humano, um cidadão. Então o acolhimento foi como para todos, não tem essa diferenciação. Uma vez que ele também passa pelos mesmos processos burocráticos, vai ser necessário adaptar a condição de trabalho para que ele execute a sua função. Nós temos que ter a clareza e a tolerância porque ele tem um outro 
tempo. Mas a intelectualidade, todo o exercício da função, capacidade dele não se discute, então a execução de documentos, isso tem um outro tempo. Mas isso não impede nada de uma boa execução. 0 acolhimento em síntese foi como todo servidor. Só na hora de operar o trabalho, daí precisa de uma adaptação (G05).

Com relação ao processo de inserção social, os gestores apontaram que, após serem feitas às adaptações necessárias nos setores para que os servidores pudessem desenvolver suas atividades da melhor forma, não foram encontradas dificuldades para essa inserção. Estas adaptações foram de estrutura física, no que tange a mesas, cadeiras e computadores. Nem todos os setores necessitaram de adaptação, já que nem todos os servidores deficientes precisam de uma adaptação específica para o desenvolvimento do seu trabalho.

[...] tentamos sempre perceber se ela estava feliz, se não estava, se ela estava gostando de fazer aquele trabalho, se ela tinha dificuldade com relação às questões físicas. Sentimos ela feliz, acho que ela se sente acolhida. A equipe é bem articulada e acho que ela se sente bem (G06).

Para Sassaki (1997), o processo de inserção social é um momento de adaptação tanto do deficiente quanto de todos que fazem parte do mesmo universo no qual ele faz parte. Neste contexto, percebemos, a partir das falas dos gestores, que a UFSC realiza um processo para conhecer este servidor que está ingressando, bem como entender sua deficiência, para poder dar todo suporte necessário e acolhimento no ambiente de trabalho no qual está sendo inserido. Este processo de inserção é gerenciado inicialmente pela EMAPCD que faz entrevista com o servidor com deficiência, e com os possíveis gestores que têm a demanda de necessidade de pessoal registrada na PRODEGESP, para receber o servidor. Depois de selecionado o ambiente que receberá o servidor com deficiência, é feito um acompanhamento pela EMAPCD e pelo DDP, durante toda a fase de desenvolvimento do seu estágio probatório.

Portanto, com base nas entrevistas, os servidores com deficiência são integrados de modo receptivo, seus ambientes de trabalho passam por adaptação, quando necessário, tornando o processo de inserção social o mais natural e acolhedor possível, para que ele sinta-se fazendo parte da Instituição.

Esta inserção do servidor no ambiente de trabalho, muito além das adaptações físicas que em algumas situações se faz necessário fazer, é pertinente o estabelecimento de ações que fundamentem uma política institucional de inclusão de servidores TAE, que os situem sujeitos pertencentes e identificados com os seus ambientes de trabalho.

Nesta perspectiva na segunda categoria, foi trabalhado a Política Institucional de Inclusão de Servidores TAE com deficiência, tendo como objetivo compreender a visão dos gestores sobre a concepção da Política Institucional e seu desenvolvimento. Cabe lembrar que tal Política versa sobre as ações que devem ser tomadas para inserção dos servidores TAE com deficiência no momento de seu ingresso na Instituição e durante todo período do estágio probatório (UFSC, 2017e).

Ao entrar em exercício, o servidor nomeado para cargo de provimento efetivo ficará sujeito a estágio probatório, durante o qual a sua aptidão e capacidade serão objeto de avaliação para o desempenho do cargo, observados os seguintes fatores: assiduidade; disciplina; capacidade de iniciativa; produtividade; responsabilidade (BRASIL, 1990). São estáveis, após três anos de efetivo exercício, os servidores nomeados para cargo de provimento efetivo em virtude de concurso público (BRASIL, 1998).

Os gestores tomam conhecimento destas ações por meio das avaliações periódicas realizadas (BRASIL, 1990), recebendo além do formulário padrão de todos os servidores, um formulário que descreve ações que devem ser tomadas para 0 atendimento das necessidades apontadas pelo servidor.

Em relação à concepção da Política Institucional de Inclusão de Servidores com Deficiência, os Gestores citaram a inclusão desses servidores atendendo à reserva de vagas exigida por meio da Lei no 8112/1990 (BRASIL, 1990), assim como o acompanhamento dos mesmos durante o estágio probatório, como pode ser visto nos seguintes comentários a seguir: 
[...] a cada tempo em tempo eles tem a avaliação do probatório. E no caso deles que têm deficiência, vem um padrão e vem um outro questionário que pra quem tem deficiência. $E$ ali eles questionam se o servidor está desempenhando suas funções adequadamente. Se tem algo no setor que esteja atrapalhando o desempenho do servidor ou algo que a gente possa fazer pra melhorar (G07).

O acompanhamento dos servidores portadores de deficiência durante o estágio probatório é gerenciado pela EMAPCD. A Equipe é responsável pelo acompanhamento dos servidores com deficiência desde seu ingresso na Instituição até o término do estágio probatório. E após este período sempre que solicitado a Equipe atua no auxílio dos setores que possuem servidores com deficiência (UFSC, 2017e).

Porém, os entrevistados desconhecem a existência de alguma outra política que trate deste assunto. Os gestores reconhecem que esses servidores são inseridos na Instituição, mas desconhecem as políticas que os acompanha ao longo da vida funcional, após o término do estágio probatório.

[...] a política de acolhimento deveria ser um pouco mais intensa, no sentido de realmente acompanhar. Existe uma comissão que faz o acompanhamento desses profissionais, mas não tem uma regularidade para poder realmente fazer um trabalho de acompanhamento. Então a pessoa chega, é acolhida, mas elas passam um bom tempo sem ter alguém que vá lá e se preocupe com as questões de acessibilidade (G02).

Ou seja, para além do acolhimento inicial, dos anos do estágio probatório, os gestores não possuem outro mecanismo institucional para acompanhamento destes servidores TAE com deficiência.

[...] se der algum problema aqui, eu como gestor, vou ter que me reportar a qual instância? O que a política de inclusão social prevê para essas situações. Então ela dá esse amparo? Eu tenho uma dificuldade na condição de trabalho para adaptar a limitação, subjetivamente eu não estou feliz aqui, esse amparo que precisa ficar um pouco mais claro para mim (G05).

Quando se trata de ações para que esses servidores possam se sentir acolhidos dentro da Instituição, todos foram unânimes em dizer que não sabem qual setor dá esse suporte a esses servidores após o término do estágio probatório.

[...] do que eu conheço dentro da UFSC, a única política que tem, é essa comissão de acompanhamento e para o estágio probatório. Eu acho que deveria ter algo que possibilitasse ao servidor ter um acompanhamento ao longo da sua trajetória na UFSC e não ficar focado apenas na parte do estágio probatório. Pois, às vezes, as necessidades das pessoas com deficiência elas não vão sanar em três anos, que é o estágio probatório. Talvez ela precise de acompanhamento por mais tempo. E aí quando acaba o estágio probatório a comissão já não se responsabiliza por isso, e nenhuma outra instância na universidade tem também essa preocupação (G02).

A maioria também sugeriu algumas ações para o fortalecimento da Política Institucional, como a criação de grupos de acolhimento de servidores com deficiência, capacitações específicas para este público, assim como facilidade no processo de aquisição de equipamentos específicos para as adaptações. Já que o processo de compra e licitação costuma ser demorado nas instituições públicas, visto que a Administração Pública deve obrigatoriamente seguir vários princípios, conforme preconizado na Lei no 8.666/93 (BRASIL, 1993).

Um dos grandes desafios da Política Institucional é desenvolver ações, além das definidas pela EMAPCD (BRASIL, 1999), que vai além do acompanhamento do servidor com deficiência apenas e somente no período do estágio probatório. Há uma lacuna, que necessita ser ocupada por meio da gestão universitária, diante de uma política institucional que acompanhe e dê agilidade de condições de trabalho em toda sua vida funcional.

De maneira geral, muitas vezes esses servidores têm que esperar cerca de seis meses ou até um ano para terem seus equipamentos adaptados e prontos para o uso. Durante esse período de espera, nem sempre eles desempenham a função para a qual foram alocados naquele setor. 
[...] pegar por tipo de deficiência e tentar fazer algum programa de capacitação ou de acolhimento deles, ou quem sabe até uma interação entre os próprios colegas para ver o que funciona dentro do ambiente de trabalho onde eles estão, ou aquela experiência que eles já tiveram negativa para compartilhar e quem sabe tentar achar alguma coisa em prol deste servidor. Eu acho que seriam pequenas ações, mas seria necessário porque tem todo esse respaldo, esse cuidado com os servidores, só que mais na teoria, na prática, depois que eles ingressam na universidade eu vejo que parece que perde um pouco do controle, o cuidado com eles (G03).

A fragilidade da política de inserção social dos servidores com deficiência, como exposto na fala dos gestores, se materializa também pela falta de preparo para acesso, como os prédios antigos sem elevadores. Neste sentido, é clara a carência de uma política institucional que materialize ações de inserção social de condições de trabalho, indo além do período eminente do estágio probatório de inclusão social.

Neste contexto, percebemos que os gestores conhecem a Política Institucional no que se refere ao ingresso desses servidores e acompanhamento dentro do estágio probatório, porém desconhecem quais ações a Instituição toma para o acompanhamento dos mesmos após o encerramento do estágio probatório, apesar de todo interesse exposto.

Há uma dicotomia vivenciada no contexto do desenvolvimento da Política Institucional de Inserção de Servidores TAE com deficiência, ou seja, há todo um processo de acolhimento do servidor, de inserção social. Todavia, após o Estágio Probatório, há ações inerentes à Política Institucional que necessitam ser socializadas aos gestores ou quiçá fomentada de manutenção da inclusão deste servidor ao seu ambiente de trabalho, a Instituição.

A terceira categoria de análise apresenta a Política Pública de Inclusão de Servidores com Deficiência, que busca investigar sua concepção e a interação desta com a Política Institucional, sob o olhar dos Gestores.

Destacamos como pontos importantes dessa política o Decreto no 3.298/99 (BRASIL, 1999), que surgiu como marco na Política Pública, pois garantiu o direito a participação de pessoas com deficiência em concursos públicos, por meio de reservas de vagas, assim como a criação do Estatuto da Pessoa com Deficiência no ano de 2015, por meio da Lei no 13.146/2015 (BRASIL, 2015), garantindo o direito à igualdade, diminuindo o índice de discriminação.

Alguns gestores revelaram em suas falas que conhecem apenas como Política Pública, que trata da inclusão de pessoas com deficiência no setor público, a reserva de vagas destinadas a pessoas com deficiência (BRASIL, 1999, Art. 37) "[...] em igualdade de condições com os demais candidatos, para provimento de cargos cujas atribuições sejam compatíveis com a deficiência de que é portador". Na fala dos Gestores, quanto à concepção de Política Pública, destacamos:

[...] não vou saber te falar detalhes sobre a política pública. Mas eu vejo que positivo. Eu acho que temos, assim como política de cotas, temos que receber essas pessoas, incluí-las e dar a elas trabalho no sentido de se sentirem úteis e não um peso para sociedade. E elas podem e têm a contribuir, só que elas têm algumas particularidades que precisam ser atendidas para que elas tenham uma condição de trabalho adequada (G06).

Porém, muito mais do que apenas incluir, é preciso pensar em ações para permanência destes sujeitos no serviço público. E alguns gestores já apontam suas visões nesta perspectiva:

[...] acho que inclusão não é apenas abrir espaço para ela poder entrar em determinado ambiente, acho que inclusão é muito mais que isso. É você no dia a dia ter todo um cuidado com essa pessoa e fazer um acompanhamento diário. Porque, a partir do momento que a pessoa entra, só para dizer que ela está inserida no ambiente público de trabalho, mas e depois? Falta um feedback, tanto do governo como das instituições (G03).

Em relação a sua interação com a política institucional, o G03 aponta que ainda é feito o mínimo que poderia ser feito, apenas para atender ao que a legislação exige. “Elas fazem o mínimo do que poderiam, não 
compreendem o todo relacionado a esse assunto. Ela é muito pontual. Ela tem pontos específicos daquilo que não podemos deixar de fazer, mas todo o resto tem deixado a desejar".

E, em sua maioria, existe um desconhecimento pelos gestores sobre as duas Políticas, tanto a Pública como a Institucional, no sentido do que é feito no processo de inserção de servidores com deficiência.

[...] não tenho acompanhado direito, não sei o que têm de resoluções, não sei se existem resoluções. A UFSC tem alguma resolução diferenciando? Talvez algo nesse sentido, em nível de Conselho Universitário, para tratar de uma forma diferenciada essas questões. Nós não temos. Tem que trabalhar essas coisas (G04).

O G02 aponta uma grande preocupação no sentindo de que a Política Pública diz o que se deve fazer, porém, nem sempre fornece mecanismos para que essas ações realmente possam ser realizadas.

[...] então o que vejo na UFSC é uma instituição que está num caminho, buscando essa prerrogativa de garantir a acessibilidade, mas ela ainda está um pouco atrasada na questão de fato efetivar a acessibilidade da pessoa com deficiência. Então precisaríamos ter outros serviços que não temos aqui. Pensando na questão de mobiliário, tecnologia assistida, espaço acessíveis, de políticas institucionais que pensem na pessoa com deficiência.

Podemos constatar, por meio das entrevistas, que a única Política Pública de fato conhecida pelos Gestores é o Decreto no 3.298/99 (BRASIL, 1999), que trata da reserva de vagas para candidatos com deficiência em concursos públicos. Não havendo conhecimento de alguma outra Política para suporte destes servidores. Além disso, os Gestores apontam, em relação a interação da Política Institucional com a Política Pública, que ainda é feito apenas o preliminar, carecendo ações para de fato implementar o processo de inserção destes servidores na UFSC, para além do estágio probatório.

A Universidade necessita apoiar-se nas Políticas Públicas existentes para inclusão de servidores com deficiência e materializar esta inclusão por meio da Política Institucional, possibilitando que seus gestores compreendam a importância desta inclusão e contribuam para que os servidores TAE com deficiência sintamse verdadeiramente acolhidos, incluídos e fazendo parte da Instituição como um todo, com mais autonomia e independência para realizar suas atividades.

As pessoas com deficiência estão atuando em todos os campos e áreas da sociedade, independente de formação, por isso precisamos pensar em acessibilidade em todos os sentidos.

\section{CONSIDERAÇÕES FINAIS}

Ao retornar ao objetivo inicialmente proposto, neste estudo (SOUSA, 2018), é possível afirmar que os gestores concebem a existência da Política de inserção social dos servidores técnico-administrativos em educação, com deficiência, da Universidade Federal de Santa Catarina, porém, esta precisa ser ampliada de acordo com a necessidade e a perspectiva de desenvolvimento dos servidores TAE com deficiência, na Instituição.

Em relação ao papel da Universidade enquanto Instituição Social (CHAUÍ, 2003), a Pesquisa (SOUSA, 2018) mostrou que os entrevistad os compreendem que a Instituição faz seu papel de incluir os servidores com deficiências por meio da reserva de vagas para ingresso em concurso público, contemplada pela Lei no 8.112/90 (BRASIL, 1990), assim como se preocupa em realizar uma inclusão acolhedora no ambiente de trabalho durante o estágio probatório, com avaliações periódicas.

Quanto à Política Institucional de inserção social de servidores técnico-administrativos em educação com deficiência, por meio da análise das entrevistas, é notório a falta de uma divulgação junto aos gestores sobre ações existentes para o atendimento do servidor com deficiência após seu estágio probatório, se elas realmente existem, como são feitas e a quem estes servidores ou seus gestores devem recorrer para serem auxiliados. Parece que passados os anos do estágio probatório, o gestor perde a referência institucional de onde recorrer ou como proceder com relação às situações apresentadas pelo servidor, agora efetivo, com deficiência. 
A construção de uma universidade inclusiva é desafiadora, pois requer, além das adequações arquitetônicas, as mudanças culturais. E, para que estas sejam feitas, é preciso que todos os segmentos se envolvam no processo, seja por meio da criação de um setor específico que atenda estes servidores (técnicos e docentes), ou por meio da ampliação do trabalho da Equipe Multiprofissional, já formada para o atendimento durante o estágio probatório. Essa deve ser uma discussão feita com toda comunidade universitária, já que ela pode beneficiar a todos os segmentos, no sentido de tornar o ambiente de trabalho mais saudável, e os servidores com identidade e pertencimento junto a Instituição onde atuam.

A Política Pública trata do acesso ao serviço público garantido por legislação específica que exige a reserva de vagas para pesso as com deficiência em concursos públicos. Porém, é preciso compreender que não basta dar acesso, é preciso trabalhar na permanência desses servidores.

Este servidor chega ao serviço público, porém, se ele não tem condição apropriada para desenvolver seu trabalho, provavelmente vai desistir ou não se sentirá motivado a estar e/ou permanecer naquele ambiente. Então, o servidor não pode ser excluído por falta de acessibilidade e por ainda não termos políticas de permanência mais efetivas.

Diante desse quadro, acreditamos que, para contribuir com a inclusão e permanência dos servidores com deficiência, é necessário que a UFSC, por meio de seus gestores, conheça mais profundamente as necessidades desses servidores e ofereça algum programa de acompanhamento durante toda sua vida funcional na Instituição.

Por meio de informações coletadas ao longo da pesquisa (SOUSA, 2018), verificamos que não há um controle do número efetivo de servidores TAE com deficiência na Instituição. 0 número de aproximadamente 72 servidores, é uma amostra baseada no ingresso desses servidores na UFSC, com informações fornecidas pela equipe que os acompanha durante o estágio probatório (EMAPCD). Porém, a Instituição não possui um controle de servidores que possam ter adquirido alguma deficiência ao longo de sua vida funcional, assim como não tem daqueles que, por ventura, deixaram de possuir a deficiência ou que se desligaram da Instituição, visto que o mapeamento é feito apenas no ingresso.

Ao final deste Estudo uma contradição se revela: ao mesmo tempo em que existe uma Política Institucional de inserção de servidores com deficiência, pautada nas diretrizes da Política Pública de inclusão destes servidores, esta é negada pela fragilidade no acompanhamento destes servidores ao longo de sua vida funcional. Ou seja, ao mesmo tempo em que a Instituição é inclusiva observando a legislação vigente de ingresso de servidores com deficiência, ela nega a inclusão por falta de uma política institucional inclusiva no desenvolvimento da carreira do servidor.

Neste sentido, com vistas ao fortalecimento da Política Institucional de inserção social de servidores técnico-administrativos em educação com deficiência, propomos que, inicialmente, seja realizado um mapeamento que indique o número de servidores com deficiência na Instituição. Para realização deste mapeamento, é necessário que, além de contar com as informações obtidas no momento de ingresso desses servidores, seja feita uma atualização da ficha funcional, solicitando dados de possíveis deficiências e possíveis necessidades de adaptação em seus ambientes de trabalho.

É preciso, também, a definição das diretrizes da PRODEGESP para que após o encerramento do estágio probatório haja acompanhamento destes servidores em seus ambientes de trabalho.

Propomos também, a formação de Gestores que trabalham com servidores com deficiência para que estes se sintam mais seguros ao receberem servidores com deficiência em seus setores. Embora haja um acompanhamento durante o estágio probatório dos servidores, muitos Gestores, passado este período, se sentem perdidos em como e aonde recorrer caso necessitem de algum suporte para seus servidores.

Além disto, propomos incluir no Planejamento Institucional ações voltadas ao acompanhamento dos servidores, técnico-administrativos e docentes, com deficiência durante sua vida funcional, fortalecendo assim, a socialização da Política de Desenvolvimento de Gestão de Pessoas.

Com vistas a melhor compreender sobre como a Política Institucional de inclusão de servidores TAE, com deficiência, a UFSC vem desenvolvendo ações pontuais de adaptações, quando necessárias no ambiente de trabalho, voltadas a esse público (SOUSA, 2018). Para tanto sugerimos que esses servido res façam parte do 
processo de formulação ou readequação de uma Política Institucional mais inclusiva, que se preocupe também com a permanência deles no ambiente de trabalho, na Instituição.

E não menos importante, talvez pensar em uma forma de captação de recursos, ou disponibilidade com maior rapidez de equipamentos e móveis para o auxílio da adaptação do ambiente de trabalho (como equipamentos, cadeiras, computadores ou mesmo adaptações de acesso) em que estes servidores desenvolvem suas funções. Além de claro, pensar em uma mudança arquitetônica, dos locais ainda não adaptados, para que estes tenham fácil acesso, sem depender de ajuda para acessar determinados locais.

A pessoa com deficiência vem lutando cada vez mais para ter independência tanto na vida pessoal, como profissional. Receber esses profissionais dentro da Instituição e lhes fornecer as ferramentas necessárias para o desenvolvimento de suas atividades, deixa de ser apenas uma obrigação legal, passa a ser um cumprimento de responsabilidade dentro da sociedade a qual está inserida. A inclusão social traz consigo a equiparação de oportunidades, em uma Universidade, como Instituição Social.

\section{REFERÊNCIAS}

BRASIL. Constituição da República Federativa do Brasil. Brasília: Senado Federal, 1988.

Lei no 7.853, de 24 de outubro de 1989. Dispõe sobre o apoio às pessoas portadoras de deficiência, sua integração social, sobre a Coordenadoria Nacional para Integração da Pessoa Portadora de Deficiência Corde, institui a tutela jurisdicional de interesses coletivos ou difusos dessas pessoas, disciplina a atuação do Ministério Público, define crimes, e dá outras providências. 1989. Disponível em: http://www.planalto.gov.br/ccivil_03/leis/L7853.htm. Acesso em: 28 dez. 2016.

Lei no 8.112, de 11 de dezembro de 1990. Dispõe sobre o regime jurídico dos servidores públicos civis da União, das autarquias e das fundações públicas federais. 1990. Disponível em: http://www.planalto.gov.br/ccivil_03/leis/L8112cons.htm. Acesso em: 10 dez.

.Lei no 8.666, de 21 de junho de 1993. Regulamenta o art. 37, inciso XXI, da Constituição Federal, institui normas para licitações e contratos da Administração Pública e dá outras providências. Diário Oficial [da] República Federativa do Brasil, Brasília, DF, 21 jun. 1993. Disponível em: <http://www.planalto.gov.br/ccivil_03/Leis//8666cons.htm>. Acesso em 25 jun. 2018.

Emenda Constitucional no 19, de 04 de junho de 1998. Modifica o regime e dispõe sobre princípios e normas da Administração Pública, servidores e agentes políticos, controle de despesas e finanças públicas e custeio de atividades a cargo do Distrito Federal, e dá outras providências. Disponível em: http://www.planalto.gov.br/ccivil_03/Constituicao/Emendas/Emc/emc19.htm\#art6. Acesso em 02 ago. 2018.

Decreto $n=3.298$, de 20 de dezembro de 1999. Regulamenta a Lei $n 07.853$, de 24 de outubro de 1989, dispõe sobre a Política Nacional para a Integração da Pessoa Portadora de Deficiência, consolida as normas de proteção, e dá outras providências. 1999. Disponível em: http://www.planalto.gov.br/ccivil_03/decreto/d3298.htm. Acesso em: 28 dez. 2016.

Lei no 10.098, de 19 de dezembro de 2000. Estabelece normas gerais e critérios básicos para a promoção da acessibilidade das pessoas portadoras de deficiência ou com mobilidade reduzida, e dá outras providências. 2000. Disponível em: http://www.planalto.gov.br/ccivil_03/leis/L10098.htm. Acesso em: 24 abr. 2017.

BRASIL. Lei no 13.146, de 06 de julho de 2015. Institui a Lei Brasileira de Inclusão da Pessoa com Deficiência (Estatuto da Pessoa com Deficiência). 2015. Disponível em: http://www.planalto.gov.br/ccivil_03/_ato20152018/2015/Lei/L13146.htm. Acesso em: 28 dez. 2016.

BIANCHETTI, Lucídio; SGUISSARDI, Valdemar. Da Universidade à commoditycidade: ou de como e quando, se a educação/formação é sacrificada no altar do mercado, o futuro da universidade se situaria em algum lugar do passado. São Paulo: Mercado de Letras, 2017. 
CAPES. Ministério da Educação e Cultura. Portal de Periódicos. 2017. Disponível em: http://www.periodicos.capes.gov.br/. Acesso em: 26 set. 2017.

CARDOSO, Nilton Orany Bonatti. Compromisso social e inclusão de pessoas com deficiência no quadro de pessoal da Universidade Federal de Santa Catarina. 2013. Dissertação (Mestrado) - Programa de PósGraduação em Administração Universitária, Universidade Federal de Santa Catarina, Florianópolis, 2013.

CERVO, Amado Luiz; BERVIAN, Pedro Alcino; SILVA, Roberto da. Metodologia Científica. 6. ed. São Paulo: Person Prentice Hall, 2007.

CHAUÍ, Marilena. A universidade sob nova perspectiva. Revista Brasileira de Educação, Rio de Janeiro, n. 24, p. 5-15, 2003.

CHEPTULIN, Alexandre. A dialética materialista: categorias e leis da dialética. São Paulo: Editora AlfaÔmega, 1982.

CHIZZOTTI, Antônio. Pesquisa qualitativa em ciências humanas e sociais. 3. ed. Petrópolis: Vozes, 2010.

DINIZ, Débora. 0 que é deficiência. São Paulo: Brasiliense, 2012.

ECO, Umberto. Por que as universidades. 2014. Disponível em:

http://marcoanogueira.blogspot.com.br|2014|06/umberto-eco-por-que-as-universidades.html. Acesso em: 25 maio 2017.

GIL, Antônio Carlos. Gestão de pessoas: enfoque nos papéis profissionais. São Paulo: Atlas, 2014.

IBGE. Características gerais da população, religião e pessoas com deficiência. Rio de J aneiro: IBGE, 2012. Disponível em:

ftp://ftp.ibge.gov.br/Censos/Censo_Demografico_2010/Caracteristicas_Gerais_Religiao_Deficiencia/caracteri sticas_religiao_deficiencia.pdf. Acesso em: 10 abr. 2017.

KAUARK, Fabiana. Metodologia da pesquisa: guia prático. Itabuna: Via Litterarum, 2010.

MACHADO, Carla Vinícia Campedelli. Inclusão do deficiente no campo de trabalho. 2001. Dissertação (Mestrado) - Programa de Pós-Graduação em Engenharia da Produção, Universidade Fed eral de Santa Catarina, Florianópolis, 2001.

MINAYO, Maria Cecília de Souza (Org.). Pesquisa Social: teoria, método e criatividade. 34. ed. Rio de J aneiro: Vozes, 2015.

REIS, Renata Pletsch. Um olhar sobre o processo de desenvolvimento da política de cultura da UFPR Litroral. 2016. Dissertação (Mestrado) - Programa de Pós-Graduação em Administração Universitária, Universidade Federal de Santa Catarina, Florianópolis, 2016.

SASSAKI, Romeu Kazumi. Construindo uma sociedade inclusiva. Rio de J aneiro: Ed W.V.A, 1997.

SOUSA, Evelise Santos. A Inclusão de Servidores Técnico-administrativos em Educação, com Deficiência: o olhar dos gestores. 2018. 63 f. Dissertação (Mestrado) - Curso de Administração Universitária, Programa de Pós-graduação em Administração Universitária, Universidade Federal de Santa Catarina, Florianópolis, 2018.

TRIVIÑOS, Augusto Nibaldo Silva. Introdução à pesquisa em ciências sociais: a pesquisa qualitativa em educação. São Paulo: Atlas, 2009.

UFSC. Plano de Desenvolvimento Institucional 2015 a 2019. Florianópolis, 2015. Disponível em: http://pdi.ufsc.br/files/2015/05/PDI-2015-2019-1.pdf. Acesso em: 09 jan. 2017.

Concursos e processos seletivos. Edital no. 015/DDP/2016. Pró-Reito ria de Desenvolvimento e Gestão de Pessoas. 2017a. Disponível em: http://concursos.ufsc.br/. Acesso em: 04 abr. 2017. 
UFSC em números. Departamento de Planejamento e Gestão da Informação. 2017b. Disponível em: http://dpgi.seplan.ufsc.br/ufsc-em-numeros/. Acesso em 06 mar. 2017.

Missão. PRODEGESP. 2017c. Disponível em: http://prodegesp.ufsc.br/apresentacao/missao/. Acesso em: 04 abr. 2017.

Atribuições. PRODEGESP. 2017d. Disponível em:

http://prodegesp.ufsc.br/apresentacao/atribuicoes/. Acesso em:04 abr. 2017.

Membros Equipe. Equipe Multiprofissional de Acompanhamento aos Servidores da UFSC com Deficiência e em Estágio Probatório. 2017e. Disponível em: http://equipepcd.paginas.ufsc.br/membrosequipe/. Acesso em: 20 jan. 2017.

Apresentação. Secretaria de Ações Afirmativas e Diversidades. 2017f. Disponível em: http://saad.ufsc.br/apresentacao/. Acesso em: 20 jan. 2017.

VERGARA, Sylvia Constant. Projetos e relatórios de pesquisa em administração. 14. ed. São Paulo: Atlas, 2013. 